\title{
Study on the Teaching Reform based on the Visual Composition of Visual Communication
}

\author{
Chen Ping \\ Guangdong University of Science \& Technology \\ Dongguan, Guangdong, China
}

\begin{abstract}
With the progress in the design field, the teaching reform of the design foundation course is also imperative. Taking the basic composition course as an example, this paper integrates the teaching situation of design basic course opened by the visual communication design major in China's colleges and universities, points out the existing problems and deficiencies, and finally proposes targeted teaching reform.
\end{abstract}

Keywords—visual communication; teaching reform; visual composition

\section{INTRODUCTION}

Visual communication design is different from the communication mode of ordinary language. It mainly uses visual symbols to convey information content, which is concrete and image. Visual communication design has a strong personal subjective color, and designers express their ideas and ideas with visual symbols, which enable people to obtain information. Visual communication design has a large amount of information, is the result of multidisciplinary intersection, and is very creative. Along with the prosperity of the social economy and the development of the humanities and social sciences, the design field has also made continuous progress. This change and development has spawned a new type of design education that is different from the traditional art form. The design foundation course should also keep up with the increasingly rich design trend, and the teaching reform of the design foundation course is imperative. The basic composition is the most important foundation course for visual communication design. Its research object is the formal law and composition law in two-dimensional space. The main goal is to cultivate students' aesthetic ability and innovative ability. The training method is to study various elements of modeling, achieve the expected goal through rigorous analysis and training, and stimulate Student thinking and inspiration. This course has a fundamental guiding effect on the learning design of visual communication design students. The author will focus on the current situation of the basic composition of higher education institutions in China, explore the problems and deficiencies, and propose teaching reform ideas in a targeted manner.

\section{Plane CONSTITUTES A TEACHING IDEA PLANE CONSTITUTES A TEACHING IDEA AND CONTENT}

The plane composition class mainly trains students from the figurative thinking of painting to the abstract thinking of design and finally serves the visual communication design. Between the characteristics of visual communication art design students, the plane composition class breaks the original three major teaching modes. It is necessary not only to grasp the basic principles and formal beauty rules of plane composition from a large number of trainings, but also to analyze the basic principles and methods of plane composition from existing excellent design works; and to pay attention to sister art such as painting, music, literature, opera, etc. Focus on the aesthetics of form from these sister art, let students pay more attention to life, and understand and master these rules from the details of life. At the same time, the layout of the teaching content of the plane should be carried out for the needs of visual communication design. This course emphasizes rational and quantitative ways for students to understand the basic elements and formal aesthetics of design. The rational method is embodied in the basic elements of points, lines and planes presented in a concise graphical way, and on the basis of students fully understanding the principles, the formal aesthetics is used to extract and reconstruct the form in the plane composition. Another goal of this course is to enhance the visual communication students' understanding of the artistic sensibility and the beauty of form. Through the formation methods and principles of points, lines and surfaces, students are evoked by the design feelings of size, reality, passion, enthusiasm, meticulousness, strength, weakening, strengthening, spreading, gathering, coordination, order, contrast, harmony. Through this teaching idea, the basic elements of the plane composition, the basic form, and the teaching content that constitutes the understanding and application of the voice are completed.

The purpose of the plane composition class is to cultivate students' abstract understanding of the basic composition of points, lines and surfaces and the ability to apply and re-create. Through the broad understanding of the macroscopic and microscopic range of points, lines and surfaces, the relationship between form, texture, area, space, rhythm and rhythm is solved, and different abstract elements are combined and created to make students Can better understand the rules of creating graphics, and then study the various possibilities of giving life and meaning to graphics. Visual Communication 
Design Students must complete the process by extracting and reconstructing points, lines, and surface shapes based on the cognitive composition of the plane, and finally transitioning to the transformation of visual communication design. 33 Plane constitutes the basic elemental cognition Plane constitutes the basic element The basic elements of the cognitive plane are points, lines, and faces. The intersection of these basic elements can form a geometric shape or an organic form. The morphological characteristics of the points are far and near, false and real, etc., and are affected by the position, quantity, arrangement and environment; the morphological features of the line have changes of curvature, repetition, intersection, virtual reality, and are the most emotional and expressive. The constituent elements; the surface is formed by the enlargement of the dots, the increase of the dispersion or the width of the lines, and the enveloping, giving a feeling of fullness, which is warm, cold, and affected by the influence of the tones, colors, mechanisms, and outer contours. Strong, soft, strong and other different feelings. The surface has the characteristics of contrast between the real and the dark, the contrast of the surface, the size, the change of the density, and the texture of the surface. The shape of any visual object is formed by the organization of these basic morphological elements of points, lines and faces. For students who have just entered the design gate, the basic elements of plane composition are particularly important. The morphological features of points, lines and faces have different "characteristics", and the same form gives different psychological effects in different organizational relationships and design environments. Therefore, the traits and emotional cognition exhibited by the individual forms and combined forms of points, lines and faces are important foundations of visual communication design. In the teaching of graphic design courses, it is necessary to use a rational and gradual approach to guide visual communication students. Perceptual cognition of form. For example, when teaching the morphological features, students can be immersed in life. The stars in the sky can be attributed to points. Traffic lights, signal lights, and distant light sources can also be attributed to points, punctuation in the article, and notes in music. It is also a point that there are stars with small size, scattered dispersion, and near and far morphological features. The signal light has a cueing effect, and the punctuation marks have a segmentation effect. Through these elements of life we are able to understand the characteristics of the points well. The characteristics of this basic element are the source of inspiration for our design. Their position distribution, shape and size will bring unexpected effects to the design. On the basis of students perceiving the psychological effects of these basic elements, through observation and comparison methods, students can experience the information conveyed by the works constructed by these basic elements, the emotions expressed and the psychological effects on people. The design with "point" as the basic element is harmonious, yet vivid and natural. The point of the sun styling gives the entire design a finishing touch. The eyecatching and suggestive role of this kind of point is very clever.

The relationship between the basic elements of the plane consists of the relationship of separation, intersection, connection, and intersection, and there is a relationship of merging, overlapping, overlapping, and shearing. Studying the spatial relationship between the basic elements, and the form formed by the configuration is the essential feature of design and plane composition. The basic forms of plane composition are repetition, gradual change, specificity, symmetry, and divergence. These basic forms are the methods and principles that are commonly used in design. When understanding the repetition, we can use many natural things and artificial objects to understand, such as fish scales, leaves, petals, and the internal structure of animals and plants, so that students can better understand. As shown in the logo design of Figure 2, this logo design is not unconstrained, but is accomplished through effective design methods based on the understanding of the repetitive composition. The repetitive composition of plant leaves in nature is a good way for students to understand the orderly beauty of this repetition. The understanding and application of this form of composition is more suitable for visually conveying the way students quickly create new forms. On the basis of the students' understanding of the basic form of the plane structure, the series of design topics of various forms are practiced through the observation of natural plants. Able to achieve the purpose of the graphic design course.

The form of the form of the plane of beauty is: change and unity, symmetry and balance, contrast and harmony, knot and rhythm, exaggeration and simplification. These forms of American law are the overall thinking and control methods for the picture, and are a summary of the experience of dealing with the overall relationship of the picture. Symmetry and equilibrium are the means to balance the picture. The central axis of symmetry is a very stable form, giving people a serious, orthodox, solemn character, but also has conservative features; contrast and harmony are the manifestations of change and unity. His two states are big contrast, minor tone, or small contrast, major harmony; festival and rhythm mainly use the concept of music to describe the visual dynamic feeling; exaggeration is the common technique of art creation, simplification is exaggerated Simplification, Peking Opera masks and martial arts novels are often full of exaggeration, exaggeration and simplification can highlight the characteristics of things. Change and unity are the general rules of these forms of beauty law. We can use the art of sisters to let students understand the importance and characteristics of these laws. For example, the unity of change as the general law is one of the laws that all art forms follow. This is reflected in art forms such as painting, music, and literature. Change is the premise of innovation and development, and unity is the realm of order and art. This is the true pursuit and value of artists and designers.

\section{THE TEACHING STATUS QUO OF THE PLANE}

At present, in the art design majors of most universities in China, the plane composition courses are more traditional teaching methods. The teacher explains the relevant theoretical knowledge in the classroom, and then arranges the hand-drawn exercises related to the theoretical knowledge. After the students conceive, the complicated drawing is carried out. After the practice, the teaching of the course is finished, and then the next course is transferred. This method has not changed since the introduction of the curriculum into the country. With the development of the times, the teaching of the plane composition curriculum should be more considering the 
integration with the professional design curriculum. Considering the transition from abstraction to concreteness, the effect of adding content should be considered while studying the form. There are also a small number of colleges and universities in China that have made reforms in the teaching of plane composition, such as changing the hand-painted to computer drawing, combining the traditional patterns of figuration with the abstract forms for teaching and practice, and combining with a teacher's project topic. Study together, etc. These methods are very good to explore and try, and there are many successful cases. However, in the teaching of the whole plane constitutes the course, these good experiences are not widely used, but only a small-scale pilot. Most college visual communication design majors and environmental art design majors have the same content. In fact, the plane composition courses in these two majors are different. The former is composed in two-dimensional space, and the latter may involve the formation of three-dimensional space. The specific problems of the plane composition course teaching are shown in the following points!

The basic content of the teaching of the plane constitutes from the point, line, face to the basic form, such as repetition, approximation, gradual change, launch, space, specific, dense, contrast, texture and so on. The plane composition course adopts the teaching method taught by the teacher's classroom, and then arranges the assignments of related topics. The work forms are mostly hand-painted. These teaching contents are the essential content of the plane composition curriculum. However, most students can't use them skillfully without the guidance of teachers, and they can't achieve the purpose of applying them. Therefore, in the process of teaching, teachers should avoid teaching these forms singly. Plane composition course teaching needs to combine professional courses and professional knowledge to effectively organize classroom teaching within the scope acceptable to students.

In the homework training of the plane-constituting course, many teachers choose to let the students draw by hand. There is nothing wrong with this. However, if the hand-painted training is too focused on whether the work is clean and tidy, this deviates from the training theme of the course. Clean and tidy is important, this requirement allows students to develop good work habits. However, if it is carried out with a stubborn and rigorous pursuit, it will not achieve the purpose of training in the plane composition course. The plane constitutes a course that understands the abstract form and creates new forms for use; it is the perception of the form of beauty; it lays the foundation for the study of other professional courses. If most of the energy is used to pay attention to the degree of exquisite hand-painting, then the teaching purpose of the plane composition course cannot be fully realized.

At present, the teaching content of the plane-constituting curriculum is mostly independent and lacks links with other courses. This connection is both vertical and horizontal. The horizontal connection lies between the same level of courses, such as the relationship between the pattern foundation and the traditional Chinese pattern; the vertical connection is related to the high-level professional courses, such as logo design, layout design, book design, packaging design, advertising design, etc. course. The vertical and horizontal connection in teaching requires teachers to have good classroom control ability, to understand the students' knowledge level, and then to use vertical and simple methods to carry out vertical and horizontal connections, examples and explanations, and lay a good foundation for professional design learning. At present, most schools' flat composition courses lack the grasp of this aspect, which is one of the reasons why the plane composition curriculum does not play a role in design education.

In the teaching, some teachers start from the textbook content, and teach the students the existing knowledge and theory. Without in-depth research and development, the teaching content is pale and weak, lacking freshness, and it is difficult to satisfy students' desire for knowledge. This has led to the low quality of professional courses in some art colleges and universities. The combination of teaching and creative practice is not close, and there is a disconnection phenomenon. This is not conducive to the expansion of students' thinking and the cultivation of innovative ability, and cannot respond to the demands of innovation in society. Such a course leads some students to understand the content of their own learning, do not understand the relationship between composition and design, and do not know how to apply innovative thinking to practical design, creativity and expressiveness have not been effectively improved. Today's basic course teaching presents a characterization that is separate from professional design courses. The basic and constitutive and professional design courses in the teaching process are not conducive to broaden students' horizons and thinking, and are not conducive to let students experience the basics of learning. The purpose of the course. The basic composition of this course is often opened in the freshman year, which has certain drawbacks. When students have just entered the school, they have limited understanding of the profession, have not mastered more professional knowledge, and are still in the stage of understanding the specific image and the mode of thinking, and have not stimulated strong imagination and creativity. Most freshmen have a shallow understanding of the design profession and lack of systematic professional knowledge, which is also a disadvantage of the basic composition of learning. Generally speaking, people's cognition of the world is biased towards sensibility, and the foundation constitutes the form beauty and composition law of the curriculum research, which summarizes things into basic points, lines and planes, according to certain rules and order in the two-dimensional plane. Re-creating, presenting different objects and combinations. Such a learning and design process is fresh and unfamiliar to students, requiring students to have a strong sense of rational thinking and form, and can move from figurative thinking to abstract thinking. Therefore, at the beginning of the study, the teacher should guide the students to actively change the mode of thinking, understand the concept of basic form and three elements, understand and extract the essential features of the object, and express the emotion in abstract form.

At present, in the teaching process of the course, teachers often adopt the methods of teachers' lectures and students' practice. First of all, the teacher explains the formal beauty rules, modeling elements, expression forms, etc. in the classroom, let the students understand the relevant concepts, and then leave the students with homework assignments, so 
that they can review and practice to achieve the purpose of consolidating the knowledge. Although some students have done a lot of exercises on the rules and textures under the class, they still don't know the connotation and characteristics of the design, and the results are not good. Practice has shown that adopting such a teaching method is not conducive to the cultivation of students' enthusiasm for learning. In the classroom teaching, there are often situations in which practice and production are emphasized, and the study and excavation of the theory are not emphasized. When teachers are in the form of formal elements such as teaching elements and formal aesthetics, they rarely analyze and discuss from the perspective of constructing principles, and it is difficult to stimulate students' potential for innovative thinking. At the end of the course, teachers often sing a one-man show. This mode of evaluation weakens students' deep understanding of the course knowledge and the extension and expansion of relevant theoretical knowledge. It also weakens students' future market competitiveness and development to some extent. potential.

\section{REFORM GOALS AND CONTENT}

Based on the curriculum design system of visual communication design, the plane composition course is an important basic course. The purpose of teaching is to teach students the knowledge related to the plane composition, and to guide students to define the learning purpose of visual communication design. After the design course to lay a solid foundation, this is one of the ultimate goals of the teaching reform. The most difficult part of the student's learning of the design course is the transition from basic to design thinking, which is the most missing point in today's design curriculum. Teachers often want students to consciously change, but this process is too long. If teachers consciously cultivate in the basic course, they will greatly mobilize the enthusiasm of students and shorten the conversion time of students. This is an important goal of teaching reform. . It is also worth considering whether the students' learning effect is not satisfactory, but their own teaching methods are appropriate. Enhancing the interaction between students and teachers and establishing an effective teaching system is the main goal of teaching reform. The evaluation system is an important criterion for the evaluation of both teaching and learning. Timely reviewing student homework, reasonably constructing the content and standards of evaluation, guiding students' innovative thinking, and conducting fair evaluation in a collaborative learning environment is an important guarantee for teaching reform.

At present, in the teaching of visual communication professional packaging design direction, some teachers explain the knowledge points of each chapter of the plane composition course too much. The explanation of the theory in the textbook is partial to mechanization, lacking the overall grasp of the plane composition course. Not prominent, which leads to the situation of students forgetting after school. In addition, the plane composition course is an important basic course for design majors. This requires teachers to take into account the subsequent design courses when constructing the objectives of the plane curriculum structure and curriculum knowledge, so that students have a comprehensive grasp of the design curriculum. Therefore, while teaching the plane to form a course, the teacher should fully carry out the design thinking training and the design knowledge transfer to the students within a limited teaching time, so that the students can carry out the next step of learning to ensure the sustainable development of the design course. . This is one of the ultimate goals of the teaching reform. The lack of interest among students is one of the reasons for the poor performance of the flat composition class. In today's era of reading pictures, if teachers still only focus on the theory in textbooks and simple homework after class, it is difficult to stimulate students' interest in this course. Today's graphic design pays special attention to the expression and development of graphic visual language. However, the layout of some colleges and universities has a single content, which is not flexible enough and deep, which leads to dull classroom, low interest of students, and poor development of design thinking ability. Therefore, it is necessary to establish a long-term incentive mechanism to fully mobilize the enthusiasm of teachers and students, prevent students from slacking their minds, encourage all students to participate, guide and train students' design thinking, and enable students to complete the transition from basic to design. This is the research focus of teaching reform.

In the past, the teaching of the plane constitutes the teaching of theoretical knowledge on the textbook; on the other hand, it is a small amount of homework. This mode of teaching may lead to too little interaction between the students and the teachers. The students are unable to understand the course knowledge or perfuse the homework, and it is difficult to achieve the teaching goals. Therefore, it is necessary to establish an efficient and in-depth teaching and practice mode so that students and teachers maintain close interactions both in class and under the class in order to enhance students' practical ability and acceptability. Plane constitutes a professional basic course. Compared with other design courses, it has certain specialities. It requires students to complete enough exercises after class to lay a solid foundation. Therefore, teachers should not only clarify the final evaluation of students, but also consider the students' comprehensive ability and curriculum participation, and design a more reasonable evaluation system, and finally give students fair results, thus mobilizing students' enthusiasm for learning and cultivating them. Teamwork.

\section{VISUAL COMMUNICATION DESIGN PROFESSIONAL FOUNDATION CONSTITUTES THE COURSE TEACHING REFORM IDEAS}

The basic composition is scientific and reasonable. In the information age, people's appreciation of design works gradually rises from the most basic visual sensory level to the thinking level. Original works and visual works with spiritual connotations are more popular among the public. Therefore, teachers need to combine the form and design thinking to eliminate the gap between the basic curriculum and the professional curriculum, and provide a bridge for students to enter the design thinking as soon as possible. In teaching, teachers can use excellent design works to encourage students to further understand the application of basic composition, and use images and digital technology to insert works or cases that can strengthen the main points of explanation in the process of interpretation, and analyze the principles of specific problems. 
Know the constituent elements of the work. For example, when analyzing the conception and composition of a work with a student, first explain the author's creative background and creative purpose, and open up the students' thinking and vision to enable them to have a deeper understanding. For the creation of visual works, professional ability is the foundation, while thinking ability and creative ability can make the work icing on the cake. Teachers can actively help students to digest theoretical knowledge and improve their professional ability in these areas. When teaching the principles of points, lines, and surfaces, students can intuitively and clearly accept these theoretical knowledge by analyzing the design elements and composition principles of posters, frame design works, and logo works. It is also possible to let students find their own cases. The way to let students feel the design elements of the work. Compared to the inherent teaching methods, this teaching method is more flexible and students can learn more.

The foundation constitutes the initial stage of teaching, thinking training is the key content, and then the application of technology. In the past, the teaching mode of "theory teaching + homework training" was inevitably mechanical and rigid, and there were certain limitations in the stimulation of students' creative thinking. Therefore, it is necessary to change the fixed teaching mode in the past, aiming at cultivating the thinking and innovation ability of the students' basic foundation, and adopting heuristic teaching to guide the thinking from figurative to abstract transformation. Through a series of analysis, combined with design practice, in-depth analysis of the design factors and characteristics of the work, and to provide students with a rich space for thinking. The whole process of explanation should be deep and simple, and teachers need to be able to guide and explain the content. From figurative thinking to abstract thinking is a difficult point in teaching. It can be inspired by simple and gradual heuristics. In response to the above problems, the author proposes the following suggestions to help teachers play a more active role in cultivating students' thinking ability. First of all, in the design of teaching plans, teachers should teach students in accordance with their aptitudes. They should not use the same kind of teaching plan to face all students. Instead, they should combine the actual situation of students and propose a diversified and diverse teaching plan to make use of the "flip classroom". The teaching mode avoids the embarrassing situation that the teaching process lacks key points, the communication between teachers and students is not timely, and the teaching adaptability is not strong. Secondly, it pays attention to cultivating students' practical ability, taking students to participate in extracurricular practice or related activities, and combining theoretical knowledge in specific practical activities to help students better understand the profound connotation of teaching. At the same time, students can be organized to set up discussion groups to discuss some specific basic components. Teachers should let students learn to accept other people's opinions in the discussion, improve their thinking ability, and transform the actual impressions into abstract planar elements while constantly diverging their thinking.
In the past, teachers began to assign homework to students after the completion of the course theory teaching. Such a teaching mode is obviously inappropriate today, and students will feel bored. If you just complete the assignment task, you have no desire to create, and such a work lacks meaning. To this end, teachers can prescribe the right medicine, and first carry out reforms from the form of operation. For example, advocating subjective design, leaving students with enough imagination and space to actively cultivate students' creative enthusiasm and creative desire. The foundation constitutes a course that emphasizes practice and sometimes practices more than theoretical knowledge. In view of the characteristics of the visual communication design profession, teachers can design some practical and flexible training topics for the requirements of the subject and the actual situation of the students. For example, in logo design, poster design, and layout design, students can better use the principle of plane composition through practice and theoretical teaching methods, and enter the design thinking of the profession as soon as possible. In this process, teachers should create a relaxed, fun, and relatively relaxed learning atmosphere, and encourage students to form unique design concepts in the discussion.

In the past, the method of completing the construction required students to spend a lot of time and effort on handpainting, and the corresponding evaluation criteria did not pay attention to whether the work content can reflect the students' thinking ideas, but had higher requirements on the degree of precision and precision. The teacher can appropriately reduce the hand-painting operation mode, and in the design of the specific work task, it advocates the operation completion mode based on the computer and hand-painted. For example, the application of the computer can be appropriately introduced, so that the hand drawing is combined with the computer drawing; the operation is completed in a sequential order, the hand drawing is used in the creative sketching stage, and the computer is used in drawing the drawing to improve the work completion efficiency. At the same time, encourage and guide students to learn to use modern tools and materials to create freely, so that students can apply more energy and time to creative design.

Establishing an effective job evaluation system is of great significance to teaching. The composition does not have to look only at the form of the work, but also the development of performance and skills. In fact, the cultivation of thinking is far more important than the training of skills. Therefore, the focus of teacher evaluation should be inclined to the work of bold breakthrough and innovation. In particular, the drafting period should allow students to comment on their own ideas, and help students to sort out and summarize the basic principles in this way to prepare for the development of more professional design talents. After the student's homework is completed, students should be arranged to evaluate each other and publish different opinions. The teacher only makes the final summary and comments, and mainly proposes the advantages and disadvantages in the homework for students' reference. This kind of evaluation method is not only conducive to the expansion of students' thinking, but also plays a role in promoting a relaxed and active classroom atmosphere. 


\section{CONCLUSION}

The graphic composition course not only can cultivate students' design practice ability, but also is a design enlightenment course to help students turn high school painting thinking into design thinking. It can help students improve their design thinking ability, graphic expression ability and, more importantly, build. The bridge from the basics to the design is an important course that teachers cannot ignore. Teachers should pay attention to the shortcomings in teaching, look at the course from the macro and micro perspectives, and do a good job of integration and connection between the courses. The main points are distinct and focused, so that they can play their due role in the professional design curriculum.

\section{REFERENCES}

[1] Wu Yuhong. Preliminary Study on Teaching Reform Based on Visual Composition of Plane Composition Course[J]. Art Education Research, 2016(11).

[2] Liu Tao. Analysis of the teaching of plane composition based on visual communication design specialty[J]. Industrial Design, 2016(7).

[3] Wang Lizhi. Teaching Reform and Practice of Plane Composition Course for Visual Communication Design Specialty[J]. Art Education, 2016(11):186-187.

[4] GUO Lin-lin. Discussion on the teaching of the plane composition course of the ring art major in higher vocational colleges[J]. Journal of Yellow River Conservancy Technical College, 2013(4):78-80.

[5] Yang Xisheng. Preliminary Study on the Teaching of Color Composition[J]. Popular Art, 2016(15).

[6] Zhang Wei. Analysis on the Application of Plane Composition Teaching Method Guided by the Circle Art Profession[J]. Juanzong, 2017(22).

[7] Li Hui. On the Teaching of Basic Courses of Art Design[J]. Education and Occupation, 2007(30): 109-109.

[8] Liu Wei. Reflections on the Teaching Reform of Plane Composition Course in Visual Communication Design Specialty[J]. Art Education, 2013(5): $149-150$

[9] Men Chao. Research on Teaching Reform of Plane Composition in Higher Vocational Education-Based on the Perspective of Advertising Design and Production Specialty[J]. Journal of Nanning Vocational and Technical College, 2015, 20(4): 81-83. 